\title{
The "Business-As-Usual" growth of global primary energy use and carbon dioxide emissions - historical trends and near-term forecasts
}

A. Jarvis and C. N. Hewitt

Lancaster Environment Centre, Lancaster University, Lancaster, A14YQ, UK

Received: 21 August 2014 - Accepted: 28 August 2014 - Published: 30 September 2014

Correspondence to: A. Jarvis (a.jarvis@lancaster.ac.uk)

and C. N. Hewitt (n.hewitt@lancaster.ac.uk)

Published by Copernicus Publications on behalf of the European Geosciences Union.

The

"Business-As-Usual" growth of global primary energy use

A. Jarvis and C. N. Hewitt

Title Page

Abstract

Introduction

Conclusions

References

Tables

Figures

14

$>$ I

4

Back

$\checkmark$

Close

Full Screen / Esc

Printer-friendly Version

Interactive Discussion 


\section{Abstract}

We analyse the global primary energy use and total $\mathrm{CO}_{2}$ emissions time series since 1850 and show that their relative growth rates appear to exhibit periodicity with a fundamental timescale of $\sim 60$ years and with significant harmonic behaviour. Quantifying 5 the inertia inherent in these dynamics allows forecasting of future "business as usual" energy needs and their associated $\mathrm{CO}_{2}$ emissions. Our best estimates for 2020 are $800 \mathrm{EJ} \mathrm{yr}^{-1}$ for global energy use and $14 \mathrm{Gt} \mathrm{yr}^{-1}$ for global $\mathrm{CO}_{2}$ emissions, with both being above almost all other published forecasts. This suggests the energy and total $\mathrm{CO}_{2}$ emissions landscape in $\mathbf{2 0 2 0}$ may be significantly more challenging than currently 10 envisaged.

\section{Introduction}

Business-As-Usual (BAU) describes the normal execution of standard functional operations within both business and government. Therefore, in the absence of any change to historic norms, global energy use and $\mathrm{CO}_{2}$ emissions must follow a Business-As15 in the evolution of the global energy system and in the absence of further novel interventions, then BAU must also provide the most likely forecasts of future energy use and emissions over timescales corresponding to the observed inertial dynamics.

In their first assessment report in 1990 the Intergovernmental Panel on Climate 20 likely impacts of inaction on climate change in addition to benchmarking various mitigato BAU, preferring instead to offer multiple and widely varying future storylines and concentration pathways without expressing their relative likelihoods of occurrence (IPCC, 2000, 2007; van Vuuren et al., 2011). Recent evidence would suggest that the global energy system has not deviated significantly from its historic growth pattern (Jarvis
ESDD

$5,1143-1158,2014$

The

"Business-As-Usual" growth of global primary energy use

A. Jarvis and C. N. Hewitt

\section{Title Page}

Abstract Introduction

Conclusions References

Tables Figures

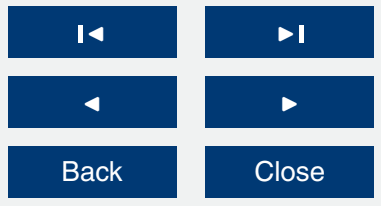

Full Screen / Esc

Printer-friendly Version

Interactive Discussion 
et al., 2012) which corresponds to the trajectories at the upper limit of the basket of the IPCC scenarios (Le Quere, 2009). This is despite the significant political efforts that have been expended to change this pattern over the last 25 years.

Because of the apparent stationarity of the dynamics of the global energy system 5 (Jarvis et al., 2012), a more accurate picture of BAU should be gained from a detailed analysis of its historic evolution. For example, the exponential growth in energy use and emissions suggests the operation of feedbacks between how humans use energy and the growth in the amount of energy they use (Garrett, 2011) and that these feedbacks are relatively stationary in the long run. Although such feedbacks cannot persist indef10 initely, investigating their behaviour over the history of industrial society could provide valuable insights into some of the processes governing energy use, albeit in highly aggregated terms. From this it should be possible to derive useful BAU forecasts of global energy use and $\mathrm{CO}_{2}$ emissions, particularly on timescales over which the internal dynamics of global energy use dominate.

15 For processes growing near exponentially, the strength of the feedbacks regulating growth can be characterised by the relative growth rates (RGRs) of these processes. If we consider the endogenous growth of global primary energy use, $x$,

$$
\frac{\mathrm{d} x(t)}{\mathrm{d} t}=a x(t)
$$

20 then $a$ is the RGR or feedback parameter for this growth process. The estimation of the RGRs from real data is straightforward if $a$ is assumed to be constant. However, because RGRs change over time in response to changes in human behaviour it is essential to also quantify their evolution over time. Estimating a directly from Eq. (1) involves utilising both the inverse and first difference of $x$ which, if the data are even modestly noisy, will lead to very poor estimates of $a$. Here we overcome this problem by exploiting a novel dynamic autoregressive framework (Young and Pedegral, 1999) to produce time varying estimates of the RGRs of global primary energy use and $\mathrm{CO}_{2}$ emissions from 1850-2010. We use these estimates to explore the dynamic variations

\section{ESDD}

$5,1143-1158,2014$

\section{The}

"Business-As-Usual" growth of global primary energy use

A. Jarvis and C. N. Hewitt

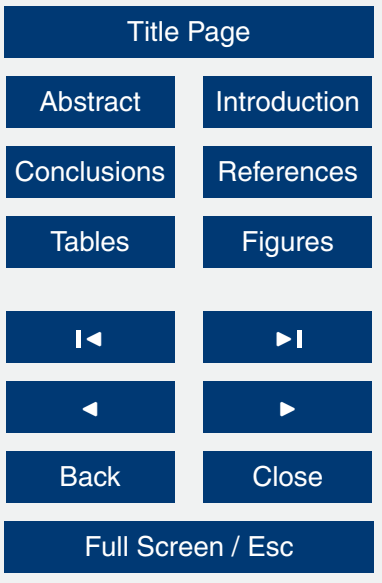

Printer-friendly Version

Interactive Discussion 
in the feedback strength of energy use on the growth in energy use and their subsequent impact on global $\mathrm{CO}_{2}$ emissions. From this analysis we construct a simple BAU forecasting regime for global primary energy use and global $\mathrm{CO}_{2}$ emissions and then use this to attempt BAU forecasts for both global primary energy use and $\mathrm{CO}_{2}$ 5 emissions.

\section{Methods}

\subsection{Global primary energy use and $\mathrm{CO}_{2}$ emissions data 1850-2010}

The global primary energy use, $x$, shown in Fig. 1a for the period 1850-2010 are taken from Jarvis et al. (2012). These data are originally from Grübler (2011) for the period 101850 to 1964 and British Petroleum (BP) for the period 1965-2010 (BP, 2011). To harmonise these two series to produce the consistent 1850 to 2010 series in Fig. 1a the mean difference between the two series for the period 1965 to $1995\left(8.3 \times 10^{18} \mathrm{~J}\right)$ was added to the BP dataset. All data were converted from tonnes of oil equivalent (toe) to Joules assuming $10^{18} \mathrm{~J}=2.38 \times 10^{7}$ toe (Sims, 2007). Global $\mathrm{CO}_{2}$ emissions data,

$15 y$, shown in Fig. 1c are taken from Houghten (2010), Boden et al. (2010) and Peters et al. (2012) and include land use change in order to complement the inclusion of wood fuel in the primary energy data. $1 \sigma$ uncertainties in the data were assumed to be $5 \%$ in energy use and fossil fuel emissions (Macknick, 2009) and $20 \%$ in land-based emissions (IPCC, 2013). $2 \sigma$ uncertainties or 95 percentile ranges in the parameter

\subsection{Estimation of relative growth rates}

The annually sampled discrete time approximation of Eq. (1) is given by the autoregressive relationship

\section{ESDD}

$5,1143-1158,2014$

The

"Business-As-Usual" growth of global primary energy use

A. Jarvis and C. N. Hewitt

Title Page

Abstract

Introduction

Conclusions References

Tables

Figures

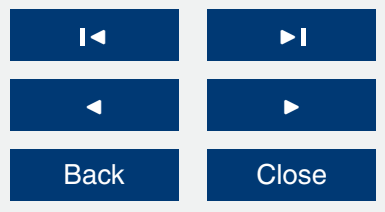

Full Screen / Esc

Printer-friendly Version

Interactive Discussion 
where we now express the RGR as a function of time. To recursively estimate the evolution of $a(t)$ from the time series of $x$ (or $b(t)$ from $y$ ), we use the dynamic autoregressive (dar) algorithm of Young and Pedegral (1999; see Young, 2011, p. 81 for details).

\section{$5 \quad 2.3$ Frequency analysis}

We estimate the frequency response of the RGRs shown in Fig. 1b. For this we have taken the frequency response of the following autoregressive relationship

$a(t)=c_{1} a(t-1)+c_{2} a(t-2)+\ldots+c_{M} a(t-M)+\xi(t)$

10 where the autoregressive (AR) parameter vector $\left[c_{1}, c_{2}, \ldots c_{M}\right]$ is estimated from the RGRs in Fig. $1 \mathrm{~b}$ and $\xi$ are the AR model residuals, taken to be an estimate of the exogenous non-periodic components of $a(t)$. Here $c$ is estimated using the nonrecursive, en bloc version of the dar algorithm. The frequency response of Eq. (3) is then given by

${ }_{15} \quad H(\omega)=\frac{\sigma^{2}}{2 \pi} \frac{1}{\left|1+c_{1} e^{(-j \omega)}+\ldots+c_{M} e^{(-j \omega)}\right|^{2}}$

where $\sigma^{2}$ is the estimated variance of $\xi$, $\omega$ are the frequencies of interest, $H(\omega)$ is power at those frequencies and $M$ is the AR model order (Young, 2011, Eq. 5.24).

Figure 2 shows the mean response for 45 AR models for $M=5$ to 50 . The reason for choosing a large range of AR models to evaluate the frequency response was to avoid prejudicing any particular AR structure. Therefore, the mean result presented in Fig. 2 should be independent of the AR structure used.

Finally, we have recovered an estimate of $\xi$ by inverting Eq. (3) on the estimates of $a(t)$ i.e.,

25

$\xi(t)=a(t)-c_{1} a(t-1)-c_{2} a(t-2)-\ldots-c_{M} a(t-M)$.
ESDD

$5,1143-1158,2014$

The

"Business-As-Usual" growth of global primary energy use

A. Jarvis and C. N. Hewitt

Title Page

Abstract

Introduction

Conclusions

References

Tables

Figures

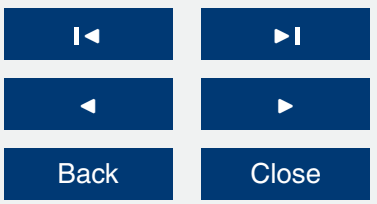

Full Screen / Esc

Printer-friendly Version

Interactive Discussion 
Again, $M=5$ to 50 was used for this and the range of the results was used as an approximate estimate of the uncertainty in these estimates shown in Fig. 1e.

\section{Results and discussion}

Our estimates of $a(t)$ are shown in Fig. 1b. The 160 year constant parameter relative 5 growth rates (RGR) estimates for $x$ and $y$ are $2.4 \pm 0.2$ and $1.8 \pm 0.4 \% \mathrm{yr}^{-1}$ respectively, the latter being less certain because historical estimates of $y$ are less certain than those of $x$. However, despite our ability to estimate these constant RGRs for $x$ and $y$ from the 160 year time series, it is clear from Fig. 1a and $c$ that there are significant variations over time in the RGRs of $x$ and $y$ about their long-term exponential trends.

10 Figure $1 b$ shows the time varying estimates of the RGRs of $x$ and $y, a(t)$ and $b(t)$. These estimates improve over time, not only because data quality improves, but also because the signal to noise ratios increases as $x$ and $y$ increase.

The changes in both $a(t)$ and $b(t)$ about their long-term mean values have slower (decadal) and faster (annual) timescale variations. To explore what timescales are im15 portant in these variations we have estimated the frequency spectrum of $a(t)$ and $b(t)$. Figure 2 shows the mean response of an ensemble estimate of the frequency spectrum of the perturbations in both $a(t)$ and $b(t)$. From this we see that both $a(t)$ and $b(t)$ appear to exhibit $\sim 60$ year periodicity with minima occurring in approximately 1870,1930 and 1990 and maxima in 1900 and 1960 (see Fig. 1b). Since these data series are

only 160 years long it is possible that the longer term variations observed in the RGRs could have arisen by chance, particularly if they were subject to the effects of random walk-type processes. However, Fig. 2 shows that $a(t)$ and $b(t)$ have frequency components close to some of the harmonics of a wave of period $\sim 60$ years. Figure 2 shows that these harmonics occur at $\sim 60 / 2=30, \sim 60 / 4=15, \sim 60 / 5=12, \sim 60 / 7=\sim 9$ $b$ did not possess $\sim 60$ year periodicity and hence provide additional support for the observed $\sim 60$ year variation being real. There also appear to be higher frequency

ESDD

5, 1143-1158, 2014

The

"Business-As-Usual" growth of global primary energy use

A. Jarvis and C. N. Hewitt

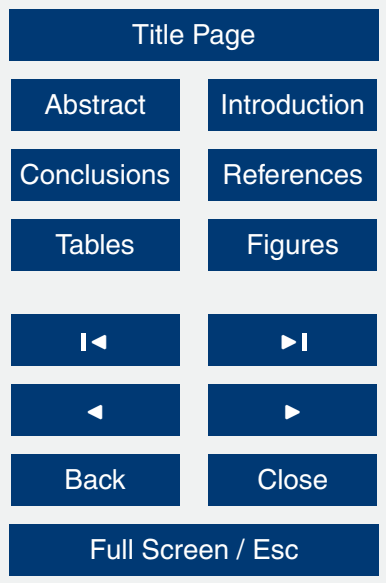

Printer-friendly Version

Interactive Discussion 
components beyond this range, but the filtering required to estimate $a(t)$ means that attributing significance to these is problematic and hence we refrain from doing so.

We note that periodic components in the observed behaviour of economic systems have assumed particular significance in the literature and have been named variously 5 (Korotayev and Tsirel, 2010). Long-wave cycles have previously been observed in the historical records of other industrial economic indicators, most significantly by Kondratieff (1925), and also more recently by Korotayev and Tsirel (2010). Kondratieff (1925) attributed periodicity in prices, interest rates, coal and iron production and other indicators of economic output, to the dynamics of capital investment. Schumpeter (1939) 10 and later Sterman (1985) attempt to explain these so-called $K$ waves by focussing on the role of the dynamics of technological innovation. Extending this framing, Modelski (1987) and Devezas and Corredine (2001) emphasised the role of adaptive learning between and within generations in giving rise to long-wave dynamics. A related possible explanation for the apparent observed periodicity in global primary energy use 15 is that waves like these are produced by complex systems constructed from discrete scale-dependent networks (Sornette, 2004). Collectively these networks may resonate as a means of identifying how to best associate uncertain environmentally-derived resources such as energy to heterogeneously distributed end users. Viewed in this way, BAU describes the global scale evolution of industrial society in the form of an optimal resource acquisition, distribution and end use network. Whatever the cause, systematic periodicity on these timescales indicates high levels of internal entrainment in the global economy in addition to high levels of inertia.

The idea that shorter-term business cycles are merely harmonics of multigenerational timescale phenonema is counter to standard economic theory but appears to deserve attention. There appears to be little consensus on the causal mechanisms of these higher frequency components (Summers, 1986). However, it is important to point out that, in terms of global primary energy use, they appear to be harmonics of $\mathrm{a} \sim 60$ year cycle and, therefore, require a unified mechanistic interpretation set within the context of a fundamental $\sim 60$ year periodic process. We note that currently
ESDD

$5,1143-1158,2014$

The

"Business-As-Usual" growth of global primary energy use

A. Jarvis and C. N. Hewitt

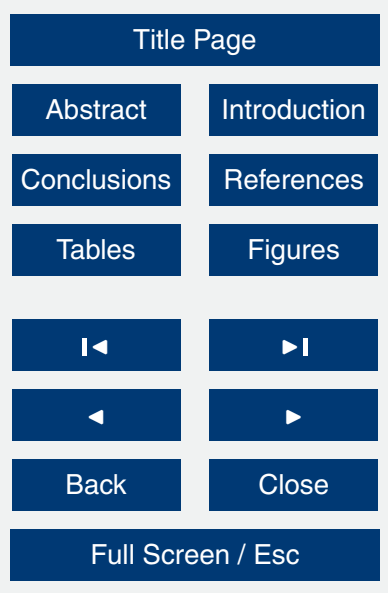

Printer-friendly Version

Interactive Discussion 
business cycles of differing durations are invariably ascribed differing causal mechanisms. Also, because energy use is so fundamental to the operation of global industrial society, it is not surprising that equivalent periodicity is exhibited in the growth rates of other economic indicators, e.g. gross domestic product (Korotayev and Tsirel, 2010) 5 as well as in primary energy use. The observation that some harmonics appear to be missing might suggest that global industrial society is behaving in a mildly nonlinear way.

The framework used to estimate the frequency spectrum in Fig. 2 also affords an estimate of the exogenous, non-periodic components of $a(t), \xi(t)$. Figure 1e shows 10 these disturbances. Clearly an element of this is the statistical uncertainty associated with the estimates of $a(t)$ given errors in the observations. We also note that it is not possible to resolve any of these disturbances for the earlier most uncertain data. However, from 1930 onwards significant exogenous shocks appear and there are three notable outliers in 1973, 1979 and 2010. The first two represent negative deviations 15 from harmonic trends and coincide with large-scale disruptions to global oil supplies, while the third (of opposite sign) appears to be come after the financial crisis of 20082009 in 2010. In terms of global energy use then, the oil crises of the 1970s appear to be far more significant than, for example, the two world wars. That the outlier in 2010 has a positive sign suggests it is a consequence of the global fiscal stimulus initiated in response to the financial crisis of 2008-2009. Therefore, in terms of global primary energy use, it was the fiscal stimulus following the crash, rather than the crash itself, that was the aberration that deviated from long-run (harmonic) trends. It therefore seems possible that, in terms of energy use, the 2008-2009 crisis was actually a systemic event arising from the transient alignment of harmonics in the performance of industrial society, rather than an exogenous shock precipitated by gross misjudgements in the global banking sector (United States Senate, 2011). In all three cases the magnitude of these exogenous disturbances appears to have been insufficient to have caused any meaningful subsequent deviation from the BAU trajectory, highlighting the inherent inertia in the use of energy by global industrial society.

\section{ESDD}

$5,1143-1158,2014$

The

"Business-As-Usual" growth of global primary energy use

A. Jarvis and C. N. Hewitt

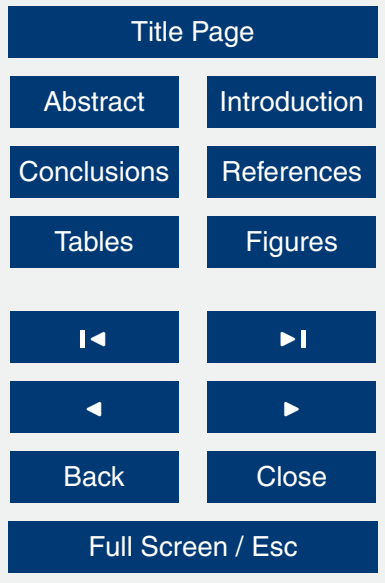

Printer-friendly Version

Interactive Discussion 
The periodicity in the RGR of $x$ and $y$ offers some predictive capability. This approach to forecasting global energy use is clearly different to that based on scenarios (e.g. SRES or RCP as used by the IPCC). Because of the repeated significant effects of the exogenous shocks on the RGRs of global primary energy use, robust forecasting 5 skill probably only exists for the $\sim 60$ year cycle and its underlying exponential growth profile with its associated growth timescale of $\sim\left(2.4 \% \mathrm{yr}^{-1}\right)^{-1} \approx 40$ years. Here we elect to forecast to 2020 using the dynamics identified in Fig. 1. We choose this timeframe because, firstly, a 60 year long-wave cycle would peak around then. Secondly, committed capital infrastructure is very unlikely to change substantially over the next 106 years without extremely radical early decommissioning of carbon-intensive energy generators and equally radical deployment of low-carbon or carbon-neutral infrastructure. Finally, and most importantly, this is the proposed date for the implementation of the Durban Platform (UNFCCC, 2013), when global energy use and climate policies have been negotiated to align. As a result, it is important to understand the energy use 15 and emissions landscape at this point in global negotiations on climate change and energy security.

To forecast energy use to 2020 we start by fitting the following summative model to the observations in Fig. 1. $a(t)$ is assumed to vary slowly and we estimate this variation simply using a cubic spline with nodes set at 1850, 2010 and 20 year increments between these two end points. The cubic spline node estimated for $a(t)$ in 2010 defines both the level and rate of change for $a(t)$ in 2010 . We assume $\mathrm{d} a / \mathrm{d} t=0$ in 2020 (i.e. at the next peak of the $\sim 60$ year cycle) and interpolate a linear transition from $\mathrm{d} a / \mathrm{d} t=0.25( \pm 0.13) \% \mathrm{yr}^{-1}$ in 2010 to zero in 2020. This RGR is then applied to forecast $x$ from 2011 to 2020 . Note that no periodic model is used here other than scaling $b=m a$ ( $m=0.74 \pm 0.09$ estimated for these data) because both $x$ and $y$ are observed to grow exponentially in the long run and there appears to be strong coherence between $a(t)$ and $b(t)$ in Fig. $1 \mathrm{~b}$ hence the systemic decarbonisation trend presented in Fig. 1d. $b$ is then applied to forecast $y$ from 2011 to 2020 . Both $m$ and the spline

\section{ESDD}

$5,1143-1158,2014$

\section{The}

"Business-As-Usual" growth of global primary energy use

A. Jarvis and C. N. Hewitt

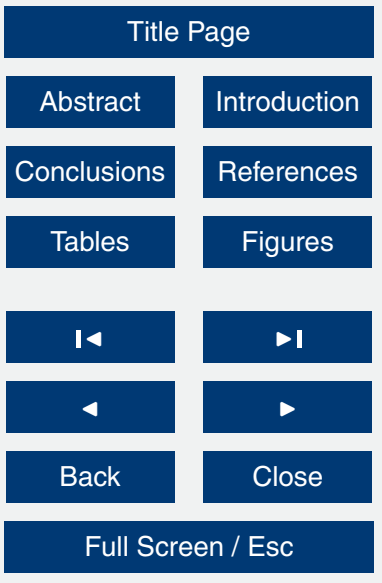

Printer-friendly Version

Interactive Discussion 
nodes for $a(t)$ are estimated using nonlinear least squares fit simultaneously to the data for both $x$ and $y$ shown in Fig. 1a and c. The assumptions used here are equivalent to a BAU scenario i.e. no meaningful intervention of additional exogenous policy measures at the global scale. Figure 1e would suggest that any such interventions aimed 5 at significantly reducing global energy use and hence $\mathrm{CO}_{2}$ emissions, would need to be similar in magnitude to the oil crisis of the 1970s, but persisting for decades. Hence we propose this is a realistic forecasting scenario until at least 2020.

The model fits and forecasts are shown in Fig. 1. Also shown are the 2020 forecasts for $x$ and $y$ for two high emission scenarios from the IPCC $(2,3)$, the International 10 Energy Agency (2011), BP (2012), Shell (2012) and ExxonMobil (2012). Our 2020 forecasts for $a$ and $b$ have mean values of $4.8( \pm 1.1)$ and $3.6( \pm 0.8) \% \mathrm{yr}^{-1}$ respectively. These are approximately twice the current energy industry growth forecasts and one and a half times greater than the IPCC's worst case A1f scenario. In contrast, the 2020 carbon intensity forecasts are all similar (see Fig. 1d). Therefore, we predict that energy use will grow faster than expected over the remainder of the decade and that the emissions landscape in 2020 will be more challenging than is currently anticipated, principally because of enhanced growth in global energy use. We estimate global energy use in 2020 will be 806 (537-1159) $\mathrm{EJ} \mathrm{yr}^{-1}$ and total $\mathrm{CO}_{2}$ emissions will be 14.3 (10.4-19.5) $\mathrm{Gt} \mathrm{yr}^{-1}$. These uncertainties are large because they include the observa20 tional uncertainties in $x$ and $y$ in addition to uncertainties generated by the forecasting. If the historic periodicity in $a$ and $b$ persists beyond 2020 there is a significant likelihood of sub-exponential growth in energy use and emissions occurring for the $\sim 30$ years beyond 2020 and we anticipate some forecasting skill from this framework for BAU over this timeframe.

\section{ESDD}

$5,1143-1158,2014$

The

"Business-As-Usual" growth of global primary energy use

A. Jarvis and C. N. Hewitt

\section{Title Page}

Abstract Introduction

Conclusions References

Tables

Figures

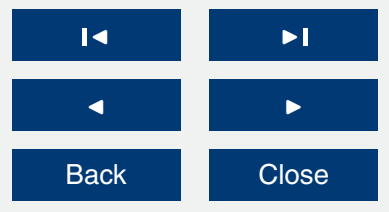

Full Screen / Esc

Printer-friendly Version

Interactive Discussion 


\section{Conclusions}

The observed persistence of the growth of global primary energy use over the last 160 years and the resultant observed growth in $\mathrm{CO}_{2}$ emissions suggests that the construction of BAU forecasts for 2020 should be based on a quantitative understanding 5 of historical trajectories. In particular, long term exponential growth of $\sim 2.4 \% \mathrm{yr}^{-1}$ has a characteristic timescale of $\sim 40$ years which is close to the observed mean lifetime of all technologies (Grubler et al., 1999) including large energy projects (Davis and Caldeira, 2010) suggesting built in persistence in this growth trajectory. Allied to this, an $\sim 60$ year periodicity in variations in the relative growth rate of primary energy use merely acts to underline the persistence of the underlying trends in this core economic determinant. As a result, we argue that, not only is there a strong observational constraint on the specification of BAU, but this state is likely to persist well after any meaningful exogenous intervention has attempted to redirect it. We argue, therefore, that BAU forecasts for 2020 (and indeed for any date in the foreseeable future) should be accepted as being the most likely, default, forecast unless and until quantitative evidence exists for deviation from the historic trajectory. The acceptance of energy and emissions scenarios or pathways based on hypothetical future actions by society should only be viewed as probable (or even possible) once such actions have been initiated. In fact, we have previously suggested that meaningful interventions in energy use and hence carbon emissions will not occur until such time as society experiences the detrimental effects of climate change (Jarvis et al., 2012).

Acknowledgements. We acknowledge the guidance provided by Peter Young to A. Jarvis on time series methods over many years. We also acknowledge helpful comments made on this work by Bron Szerszynski and Stephen Jarvis. A. Jarvis was supported by EPSRC grant
ESDD

$5,1143-1158,2014$

The

"Business-As-Usual" growth of global primary energy use

A. Jarvis and C. N. Hewitt

Title Page

Abstract

Introduction

Conclusions References

Tables

Figures

14

4

Back

Full Screen / Esc

Printer-friendly Version

Interactive Discussion 


\section{References}

Boden, T. A., Marland, G., and Andres, R. J.: Global, regional, and national fossil-fuel $\mathrm{CO}_{2}$ emissions, in: TRENDS: a Compendium of Data on Global Change, Carbon Dioxide Information Analysis Center, Oak Ridge National Laboratory, US Department of Energy, Oak Ridge, Tenn., USA, doi:10.3334/CDIAC/00001_V2010, 2010.

British Petroleum: British Petroleum Statistical Review of World Energy 2011, available at: http://www.bp.com/assets/bp_internet/globalbp/globalbp_uk_english/reports_ and_publications/statistical_energy_review_2011/STAGING/local_assets/spreadsheets/ statistical_review_of_world_energy_full_report_2011.xls (last access: 11 May 2012a), 2011.

British Petroleum: BP Energy Outlook 2030, BP London, available at: http://www. bp.com/liveassets/bp_internet/globalbp/STAGING/global_assets/downloads/O/2012_ BP-Energy-Outlook-2030-summary-tables.xls, last access: 11 May 2012b.

Davis, S. J., Caldeira, K., and Matthews, D. H.: Future $\mathrm{CO}_{2}$ emissions and climate change from existing energy infrastructure, Science, 329, 1330-1333, 2010).

Devezas, T. C. and Corredine, J. T.: The biological determinants of long-wave behaviour in socioeconomic growth and development, Technol. Forecast. Soc., 68, 1-57, 2001.

ExxonMobil: The Outlook for Energy: a view to 2040, available at: exxonmobil.com/ energyoutlook, last acccess: 11 May 20122012.

20 Garrett, T.: Are there basic physical constraints on future anthropogenic emissions of carbon dioxide?, Climatic Change, 104, 437-455, 2011.

Grübler, A.: World Primary Energy Use, http://iiasa.ac.at/gruebler/Data/ TechnologyAndGlobalChange/w-energy.csv, last access: 12 October 2011.

Grübler, A., Nakienovic, N., and Victor, G. B.: Dynamics of energy technologies and global change, Energ. Policy, 27, 247-280, 1999.

Houghton, R. A.: Carbon flux to the atmosphere from land-use changes: 1850-2005, in: TRENDS: a Compendium of Data on Global Change, Carbon Dioxide Information AnalysisCenter, Oak Ridge National Laboratory, US Department of Energy, Oak Ridge, Tenn., USA, doi:10.3334/CDIAC/00001_V2010, 2010.

30 Intergovernmental Panel on Climate Change Report: Climate Change, The IPCC Response Strategies 1990, World Metrological Office, 2013.
ESDD

$5,1143-1158,2014$

The

"Business-As-Usual" growth of global primary energy use

A. Jarvis and C. N. Hewitt

Title Page

Abstract

Introduction

Conclusions References

Tables

Figures

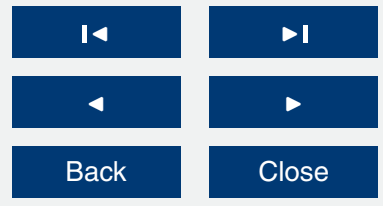

Full Screen / Esc

Printer-friendly Version

Interactive Discussion 
Intergovernmental Panel on Climate Change: Emissions Scenarios, edited by: Nakicenovic, N. and Swart, R., Cambridge University Press, UK, 570 pp., 2000.

Intergovernmental Panel on Climate Change: Expert Meeting Report: Towards new scenarios for analysis of emissions, climate change, impacts, and response strategies, 19-21 Septem-

5 ber 2007, Noordwijkerhout, the Netherlands available at: http://www.aimes.ucar.edu/docs/ IPCC.meetingreport.final.pdf, last access: 11 October 2013.

Intergovernmental Panel on Climate Change: 5th Assessment Report, chap. 6, available at: http://www.climatechange2013.org/images/uploads/WGIAR5_WGI-12Doc2b_FinalDraft_ Chapter06.pdf, last access: 30 October 2013.

10 International Energy Agency: World Energy Outlook 2011, IEA Publications, Paris, 2011.

Kondratiev, N. D.: The Major Economic Cycles (Moscow, 1925), translated and published as The Long Wave Cycle, Richardson \& Snyder, New York, 1984.

Korotayev, A. V. and Tsirel, S. V.: A Spectral Analysis of World GDP Dynamics: Kondratieff Waves, Kuznets Swings, Juglar and Kitchin Cycles in Global Economic Development, and the 2008-2009 Economic Crisis, Struct. Dynam., 4, 1, 2010.

Jarvis, A., Leedal, D. T., and Hewitt, C. N.: Climate-society feedbacks and the avoidance of dangerous climate change, Nat. Clim. Change, 2, 668-671, 2012.

Le Quere, C., Raupach, M. R., Canadell, J. G., Marland, G., Bopp, L., Ciais, P., Conway, T. J., Doney, S. C., Feely, R. A., Foster, P., Friedlingstein, P., Gurney, K., Houghton, R. A., House, J. I., Huntingford, C., Levy, P. E., Lomas, M. R., Majkut, J., Metzl, N., Ometto, J. P., Peters, G. P., Prentice, I. C., Randerson, J. T., Running, S. W., Sarmiento, J. L., Schuster, U., Sitch, S., Takahashi, T., Viovy, N., van der Werf, G. R., and Woodward, F. I.: Trends in the sources and sinks of carbon dioxide, Nat. Geosci., 2, 831-836, 2009.

Macknick, J.: Energy and carbon dioxide emission data, IIASA Interim Report IR-09-032, 2009.

Peters, G. P., Marland, G., Le Quéré, C., Boden, T., Canadell, J. G., and Raupach, M. R.: Rapid growth in $\mathrm{CO}_{2}$ emissions after the 2008-2009 global financial crisis, Nat. Clim. Change, 2, 2-4, 2012.

Schumpeter, J. A.: Business Cycles: a Theoretical, Historical and Stastistical Analysis of the Capitalist Process, Martino Publishing, McGraw Hill, New York, 1939.

30 Shell: Shell Energy Scenarios to 2050, available at: shell.com/scenarios, last access: 11 May 2012.

\section{ESDD}

$5,1143-1158,2014$

\section{The \\ "Business-As-Usual" growth of global primary energy use}

A. Jarvis and C. N. Hewitt

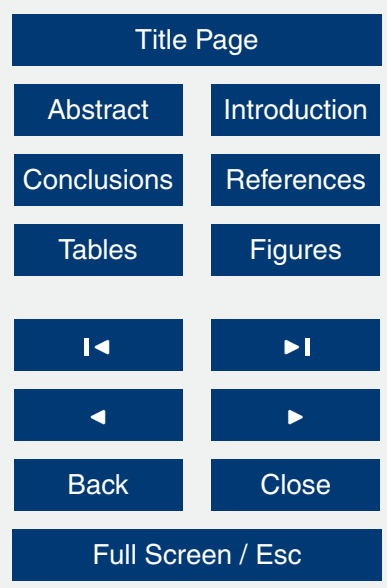

Printer-friendly Version

Interactive Discussion 
Sims, R. E. H., Schock, R. N., Adegbululgbe, A., Fenhann, J., Konstantinaviciute, I., Moomaw, W., Nimir, H. B., Schlamadinger, B., Torres-Martínez, J., Turner, C., Uchiyama, Y., Vuori, S. J. V., Wamukonya, N., and Zhang, X.: Energy supply, in: Climate Change 2007, Mitigation, Contribution of Working Group III to the Fourth Assessment Report of the Intergovernmental Panel on Climate Change, edited by: Metz, B., Davidson, O. R., Bosch, P. R., Dave, R., and Meyer, L. A., Cambridge, 2007.

Sornette, D.: Why Stock Markets Crash, Critical Events in Complex Financial System, Princeton University Press, Philidelphia, 2004.

Sterman, J. D.: The economic long wave: theory and evidence, Alfred P. Sloan School of Management Working Paper WP-1656-85, Massachusetts Institute of Technology, available at: http://dspace.mit.edu/bitstream/handle/1721.1/47592/economiclongwave00ster.pdf (last access: 20 October 2013), 1985.

Summers, L. H.: Some sceptical observations on real business cycle theory, Federal Reserve Bank of Minneapolis Quarterly Review, 10, 23-27, 1986.

UNFCCC: Draft decision-/CP.17, Durban, South Africa, available at: http://unfccc.int/resource/ docs/2011/cop17/eng/l10.pdf, last access: 22 June 2013.

United States Senate: Wall Street and the Financial Crisis, Anatomy of a Financial Collapse, Report of the Permanent Subcommittee of Investigations, USS Publications, Washington, 2011.

van Vuuren, D. P., Edmonds, J., Kainuma, M., Riahi, K., Thomson, A., Hibbard, K., Hurtt, G. C., Kram, T., Krey, V., Lamarque, J.-F., Masui, T., Meinshausen, M., Nakicenovic, N., Smith, S. J., and Rose, S. K.: The representative concentration pathways: an overview, Climatic Change, 109, 5-31, 2011.

Young, P. C.: Recursive Estimation and Time Series Analysis, Springer, Berlin, 2011. Appl. Stat., 26, 103-128, 1999.

ESDD

$5,1143-1158,2014$

The

"Business-As-Usual" growth of global primary energy use

A. Jarvis and C. N. Hewitt

Title Page

Abstract

Introduction

Conclusions References

Tables

Figures

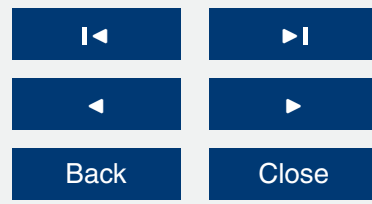

Full Screen / Esc

Printer-friendly Version

Interactive Discussion 


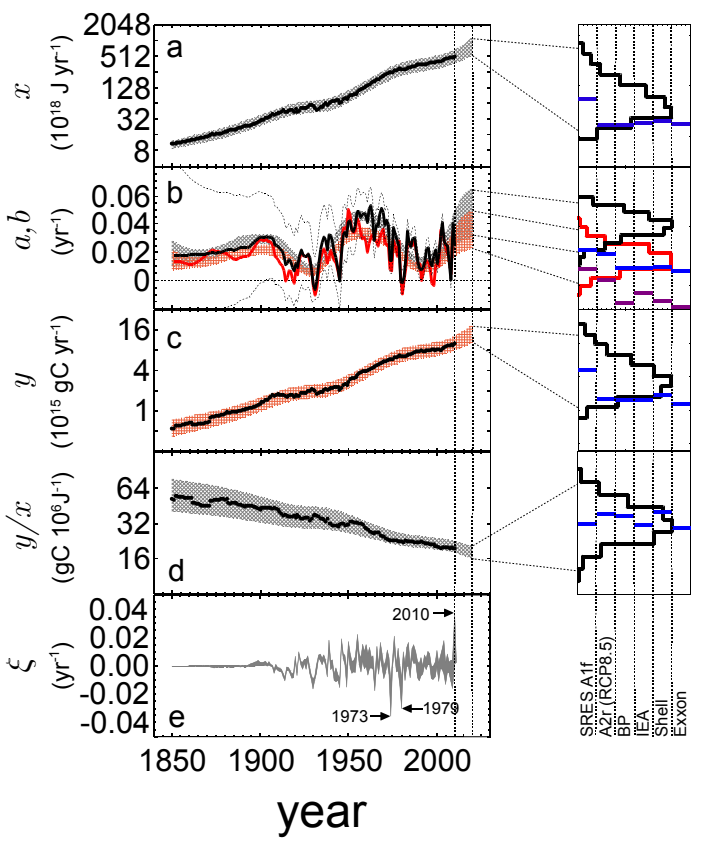

Figure 1. (a) $x$ is global primary energy use. (b) $a, b$ are the RGRs on global primary energy use (black) and global $\mathrm{CO}_{2}$ emissions (red). (c) $y$ is global anthropogenic $\mathrm{CO}_{2}$ emissions (3, $4,5)$. (d) $y / x$ is the carbon intensity of global primary energy. The forecasts for 2011-2020 are based on the assumption that $\dot{a}=0$ in 2020 and that $b=0.74 a$. The bands represent 5 th to 95th uncertainty ranges when estimating and forecasting the RGRs. The frequency distributions for the 2020 forecasts of $x, a, b, y$ and $x / y$ in (a)-(d) are shown in addition to the equivalent forecasts from a range of alternative sources as identified. The ensembles used to construct the distribution for 2020 for $x, a, b, y$ and $x / y$ are generated from an $N=10^{3}$ Monte Carlo simulation drawing from the estimated covariances derived from the model fitting. (e) An estimate of the exogenous, non-periodic components of $a(t)$. Again the band represents $95 \%$ uncertainty. See Methods for data details.
ESDD

5, 1143-1158, 2014

\section{The \\ "Business-As-Usual" growth of global primary energy use}

A. Jarvis and C. N. Hewitt

Title Page

Abstract

Introduction

Conclusions

References

Tables

Figures

14

4

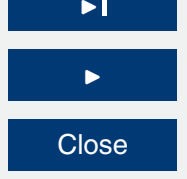

Back

Close

Full Screen / Esc

Printer-friendly Version

Interactive Discussion 


\section{ESDD}

$5,1143-1158,2014$

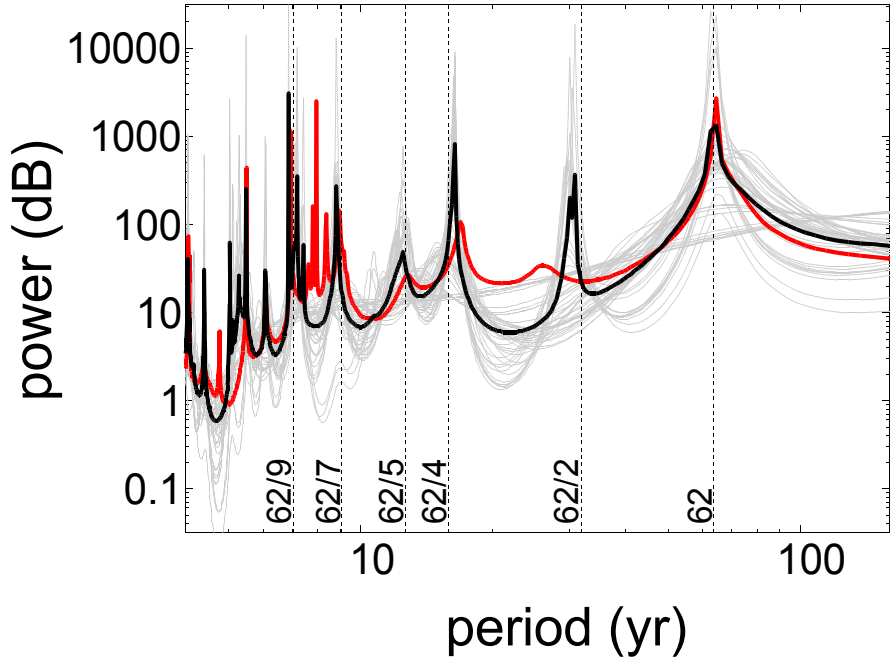

Figure 2. The period (frequency ${ }^{-1}$ ) power relationship for the RGR estimates for global primary energy, shown in Fig. 1b (-). The grey lines are the spectra of all individual autoregressive models (5th to 50th order) fitted to these relative growth rate series of which the black line is the mean spectra. The vertical lines mark the 62 year cycle and its harmonics. Also shown is the spectra for the RGR estimates for the $\mathrm{CO}_{2}$ emissions shown in Fig. $1 \mathrm{~b}(-)$.

\section{The}

"Business-As-Usual" growth of global primary energy use

A. Jarvis and C. N. Hewitt

\section{Title Page}

Abstract

Introduction

Conclusions

References

Tables

Figures

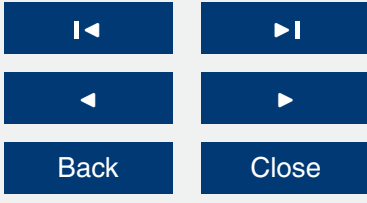

Full Screen / Esc

Printer-friendly Version

Interactive Discussion 